\title{
Pusat Komunitas Tunarungu: Mata yang Mendengar
}

\author{
Cinthia Sofie Devansari dan Murni Rachmawati \\ Departemen Arsitektur, Fakultas Teknik Sipil dan Perencanaan, Institut Teknologi Sepuluh Nopember (ITS) \\ e-mail: murnirach@arch.its.ac.id
}

\begin{abstract}
Abstrak-Sebagai seseorang yang memiliki ketidaksempurnaan, tunarungu sering mengalami permasalahan tersendiri dalam hidupnya. Yang pada akhirnya permasalahan-permasalahan tersebut mempengaruhi kualitas hidup tunarungu, dimana para tunarungu memiliki kualitas hidup yang buruk karena merasa dikucilkan, tidak dianggap dan tunarungu juga kesulitan dalam memenuhi kebutuhan finansialnya. Padahal sebagai umat manusia, para tunarungu berhak untuk mendapatkan kehidupan yang layak, sama seperti manusia normal lainnya. Penjabaran di atas melatarbelakangi diperlukannya Pusat Komunitas Tunarungu yang nantinya diharapkan dapat menjadi wadah bagi tunarungu dalam mengembangkan minat dan bakatnya, sekaligus wadah dalam memamerkan dan menunjukan kemampuan dan bakatnya kepada masyarakat luas. Pendekatan DeafSpace dan juga konsep "Mata yang Mendengar" diterapkan dalam objek rancang ini. Pendekatan dan konsep ini dipakai dan diterapkan untuk membuat sebuah objek rancang yang desainnya sesuai dengan kebutuhan seorang tunarungu, baik dari sisi gubahan massa, tatanan zoning, hingga penggunaan material dan warna pada bangunan. Dengan desain objek rancang yang sesuai dengan kebutuhan tunarungu ini, maka diharapkan para tunarungu dapat beraktivitas dengan nyaman dan aman.
\end{abstract}

Kata Kunci-Tunarungu, Kualitas Hidup, Minat dan Bakat, Masyarakat.

\section{PENDAHULUAN}

$\mathrm{T}$ UNA RUNGU adalah seseorang yang mengalami kekurangan atau kehilangan kemampuan mendengar baik sebagian atau seluruhnya yang diakibatkan karena tidak berfungsinya sebagian atau seluruh alat pendengaran, sehingga ia tidak dapat menggunakan alat pendengarannya dalam kehidupan sehari-hari yang membawa dampak terhadap kehidupannya secara kompleks. Berdasarkan data yang dihimpun oleh Susenas pada tahun 2012, dinyatakan bahwa $2,45 \%$ atau sekitar 6.049.050 jiwa penduduk dari total 246.900.000 jiwa penduduk Indonesia menyandang disabilitas fisik [1]. Dari jumlah tersebut, 7,87\% atau sekitar 476.060 jiwa penduduk adalah tunarungu. (Gambar 1) Jumlah ini akan terus bertambah seiring dengan tingginya angka kelahiran, kecelakaan dan maraknya penyakit yang beredar di tengah masyarakat.

Dengan jumlah yang cukup banyak tersebut, ternyata tidak dapat menjamin kesejahteraan hidup para tunarungu. Berdasarkan data Susenas tahun 2012, sebesar 81,81\% penyandang disabilitas fisik tidak bersekolah, tidak lulus SD dan hanya lulus SD. (Gambar 2) Penyandang disabilitas fisik juga rentan digolongkan dalam masyarakat miskin, dimana hanya $37,85 \%$ penyandang disabilitas fisik yang memiliki pekerjaan (Gambar 3).



Gambar 1. Persentase Tunarungu tahun 2012.

(Sumber: BPS)

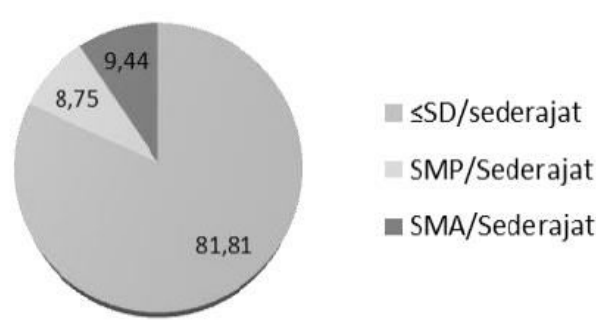

Gambar 2. Persentase Tingkat Pendidikan.

(Sumber: BPS)

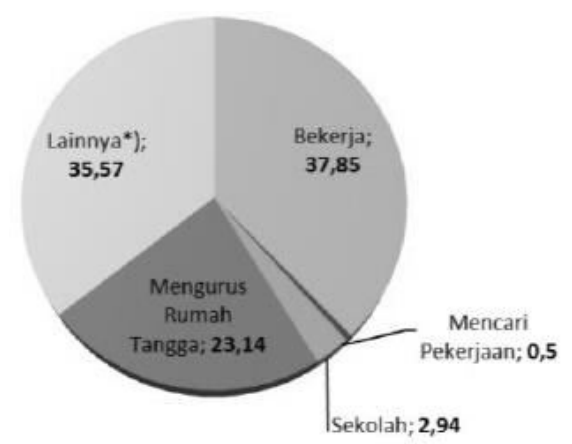

Gambar 3. Persentase Jenis Pekerjaan.

(Sumber: BPS)

Kualitas hidup yang tidak baik ini, tidak muncul dengan sendirinya. Melainkan disebabkan oleh beberapa faktor. Yang pertama yaitu faktor diskriminasi. Selama ini masyarakat 
memperlakukan para tunarungu secara berbeda didasari oleh asumsi atau prasangka bahwa dengan kekurangan yang mereka miliki, para tunarungu dianggap tidak mampu beraktivitas dan berkomunikasi sebagaimana orang lain pada umumnya. Selanjutnya yaitu faktor kurangnya atau bahkan tidak adanya sarana dan prasarana khusus yang ada di fasilitas umum juga menjadi permasalahan yang cukup besar bagi tunarungu. Dimana pada fasilitas umum seperti sekolah, kampus, rumah sakit, terminal dan lain-lain yang seharusnya bisa dikunjungi dan digunakan oleh setiap orang, pada faktanya sulit atau bahkan tidak aman untuk dikunjungi dan digunakan oleh para tunarungu.

Padahal sebagai seorang manusia, para tunarungu juga memiliki hak untuk mendapatkan pendidikan, keterampilan, pekerjaan, kemapanan ekonomi dan juga kehidupan sosial yang baik sama seperti manusia normal pada umumnya. Berdasarkan hal tersebut, munculah penyelesaian yang diusulkan yaitu objek rancang berupa Pusat Komunitas Tunarungu. Objek rancang ini memiliki berbagai fasilitas yang disesuaikan dengan tujuan objek rancang yaitu untuk membantu tunarungu dalam mendapatkan hak-haknya akan pendidikan, keterampilan, pekerjaan, kemapanan ekonomi dan juga kehidupan sosial yang baik.

\section{PENDEKATAN DAN METODA DESAIN}

\section{A. Pendekatan Desain}
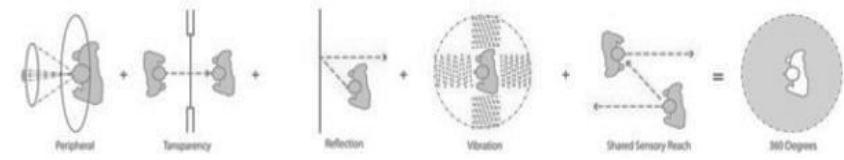

Gambar 4. Pendekatan DeafSpace untuk Tunarungu. (Sumber: www.gallaudet.edu)

Tunarungu memiliki dunia yang kaya akan sensorik, dimana pengelihatan dan sentuhan menjadi sarana utama dalam kesadaran ruang dan orientasi. Kepekaan dan pengalaman hidup dibangun dengan menggunakan banyak tanda bahasa, mode komunikasi visual dan pemeliharaan identitas budaya yang kuat. Lingkungan kita dibangun sebagian besar oleh dan untuk pendengaran individual. Hal ini menyulitkan para penyandang tunarungu dalam merespon lingkungan karena keterbasan mereka. DeafSpace diciptakan sebagai suatu pendekatan untuk mengubah lingkungan menjadi lebih ramah terhadap penyandang tunarungu [2]. Adapun beberapa konsep dari pendekatan DeafSpace, yaitu sebagai berikut:

\section{1) Sensory Reach}

Orientasi ruang dan kesadaran akan kegitan dalam lingkungan sangat penting untuk mempertahankan rasa kesejahteraan. Penyandang tunarungu "membaca" kegiatan di sekitarnya melalui sensitivitas, isyarat visual dan taktil, seperti gerakan bayangan, getaran atau bahkan pergeseran halus dalam ekspresi atau posisi orang lain di sekitarnya. Banyak aspek dalam bangunan yang dapat dirancang untuk memfasilitasi kesadaran ruang dan orientasi dengan menggunakan pandangan 360 derajat.

\section{2) Space and Proximity}

Demi mempertahankan komunikasi visual antar individu, dibutuhkan jarak dimana para penyandang tunanetra dapat melihat ekspresi dan dimensi wajah lawan bicara secara jelas. Jarak yang dibutuhkan untuk berkomunikasi secara visual lebih besar daripada berkomunikasi secara lisan. Jika komunikasi visual dilakukan dengan banyak orang atau berkelompok, maka dibutuhkan ruang yang lebih besar agar setiap individu dapat melihat seluruh lawan bicara secara jelas. Hal tersebut mempengaruhi perancangan layout dan ruang dari sebuah bangunan.

\section{3) Mobility and Proximity}

Ketika berjalan bersama, para penyandang tunarungu cenderung menjaga jarak agar mendapatkan komunikasi visual yang jelas. Para penyandang juga akan mengubah-ubah pandangan mereka antara lawan bicara dan lingkungannya demi menghindari adanya bahaya dan mempertahankan arah yang tepat. Jika terdapat bahaya, mereka akan langsung bereaksi, menyesuaikan dan menghindarinya. Diperlukan desain sirkulasi dan ruang berkumpul yang tepat, sehingga memungkinkan para penyandang tunarungu terus melakukan perbincangan tanpa mendapat gangguan.

\section{4) Light and Color}

Kondisi pencahayaan yang buruk seperti silau, pola bayangan, backlighting yang mengganggu komunikasi visual, merupakan kontributor utama penyebab kelelahan pada mata yang menyebabkan hilangnya konsentrasi dan bahkan kelelahan fisik. Penggunaan pencahayaan buatan yang tepat dan desain elemen arsitektur yang dapat mengontrol pencahayaan alami dapat dikonfigurasi untuk memberikan cahaya yang lembut dan menyebar cahaya yang sesuai dengan kenyamanan mata. Warna dapat digunakan untuk membuat kontras warna kulit agar menyoroti bahasa isyarat dan memfasilitasi komunikasi visual.

\section{5) Acoustics}

Penyandang tunarungu memiliki beberapa macam dan derajat kesulitan mendengar, sehingga banyak perangkat diciptakan untuk membantu mereka mendengar seperti alat bantu dengar atau implan koklea. Terkadang para penyandang tunarungu yang memakai alat bantu dengar tersebut merasa tidak nyaman bahkan kesakitan, akibat adanya gema yang disebabkan oleh pantulan gelombang suara pada permukaan bangunan yang keras. Sehingga setiap ruang harus dirancang untuk mampu mengurangi gema dan sumber kebisingan latar belakang.

\section{B. Metoda Desain}

Dalam buku yang berjudul Basic Design Methods, Kari Jormakka mengatakan bahwa setiap arsitek membutuhkan metode dalam menyelesaikan setiap permasalahan dan membantu arsitek dalam menentukan sebuah keputusan yang tepat. Pada kesempatan ini metode yang dipilih berdasarkan buku Basic Design Methods adalah metode Rationalist Approach atau pendekatan rasional [3]. Pendekatan rasional 
sendiri terdiri dari dua hal yaitu Performance Form (Bentuk Kinerja) dan Design Research (Riset Desain).

Dalam konsep pemrograman ruang yang ada di objek rancang ini banyak mengaplikasian teori Trans Programming yang ditulis oleh Bernard Tschumi dalam buku Six Concepts Excerpt from Architecture and Disjunction. Dalam hal ini terdapat tiga program ruang yang dihadirkan dalam objek rancang, yaitu program ruang untuk pelatihan minat bakat, program ruang untuk pemeriksaan pendengaran, dan yang terakhir adalah program ruang untuk terapi dan pelatihan bahasa isyarat [4]. Ketiga program ruang tersebut tidak saling berhubungan, namun saling mendukung dalam usulan objek rancang.

Dalam pembentukan masa bangunan, digunakan grid 2 dimensi yang membagi lahan dalam beberapa bagian. Setelah membagi lahan dengan grid 2 dimensi, kemudian dilanjutkan dengan pembuatan grid 3 dimensi yang meninggi ke atas. Grid yang telah terbentuk tersebut dijadikan sebagai acuan dalam menempatkan ruang, pembentukan ruang, serta penempatan struktur bangunan. Hal ini diharapkan dapat memenuhi kebutuhan ruang yang ada, dan juga dapat mempermudah penempatan struktur yang digunakan (Gambar 5).

\section{KONSEP DESAIN}

\section{"Ketika dua orang tunarungu berbicara, arsitektur menjadi} orang ketiga.'

Mata yang Mendengar dipilih sebagai konsep yang akan diterapkan pada objek rancang ini. Berbeda dengan manusia normal lainnya, aktivitas mendengar yang dilakukan oleh tunarungu tidak berpusat pada telinga, melainkan mata [5]. Mata menjadi jendela untuk tunarungu dalam mencari dan menerima informasi yang terjadi di sekitarnya. Dalam hal ini kebebasan dan kejelasan untuk melihat adalah hal yang sangat penting. Selain untuk komunikasi, hal ini penting untuk proteksi diri dan juga navigasi (wayfinding).

Karena banyak mengandalkan akses visual, maka desain bangunan ini diharapkan tidak terlalu membatasi pandangan tunarungu, dimana dalam hal ini sudut pandang ruang menjadi hal yang sangat penting. Para tunarungu akan merasa lebih nyaman dan aman jika mereka berada di ruang yang memiliki sudut pandang luas. Di sisi lain, sama seperti manusia normal lainnya, para tunarungu juga memiliki kebutuhan akan privasi. Dengan demikian, keseimbangan antara akses visual tinggi dan juga terjaganya privasi menjadi hal yang sangat penting dalam objek rancang ini.

Tidak hanya berfokus pada mata saja, konsep ini akan lebih baik dan ideal jika ini dikombinasikan dengan penggunaan panca indera yang lain, yaitu dengan melibatkan indera peraba yang dapat merasakan getaran. Ketika berada di sebuah ruang dengan akses visual terbatas, seorang tunarungu akan kesulitan untuk mengetahui dan mencari informasi tentang apa yang terjadi di luar ruangan tersebut. Di sini unsur getaran menjadi hal yang penting untuk dihadirkan. Misalnya dengan penggunaan lantai papan kayu yang bisa menimbulkan getaran tertentu yang dapat dirasakan tunarungu saat terdapat orang yang berjalan melewatinya di balik dinding.
Berdasarkan penjelasan di atas, dapat disimpulkan bahwa konsep "Mata yang Mendengar" yang diterapkan pada objek rancang, menitik beratkan pada penggunaan indera pengelihatan (visual) dan juga indera peraba (sentuhan). Penggunaan kedua indera ini diterapkan untuk memenuhi kebutuhan tunarungu di dalam sebuah arsitektur, kebutuhan tersebut antara lain adalah:

1. Komunikasi Visual

2. Sensory Reach

3. Navigasi (wayfinding)

\section{PENERAPAN KONSEP DESAIN}

\section{A. Konsep Tapak}

Desain tapak banyak dipengaruhi oleh kondisi lingkungan serta bentuk dari bangunan ini sendiri. Karena bangunan ini memiliki bentuk bulat-bulat, maka desain tapak yang dihadirkan berupa kotak-kotak sehingga terkesan lebih dinamis. Pola material pada tapak juga dipilih dan dipasang sedemikian rupa agar mampu menuntun tunarungu secara visual, sehingga kebutuhan tunarungu akan navigasi akan mudah untuk terpenuhi (Gambar 6).

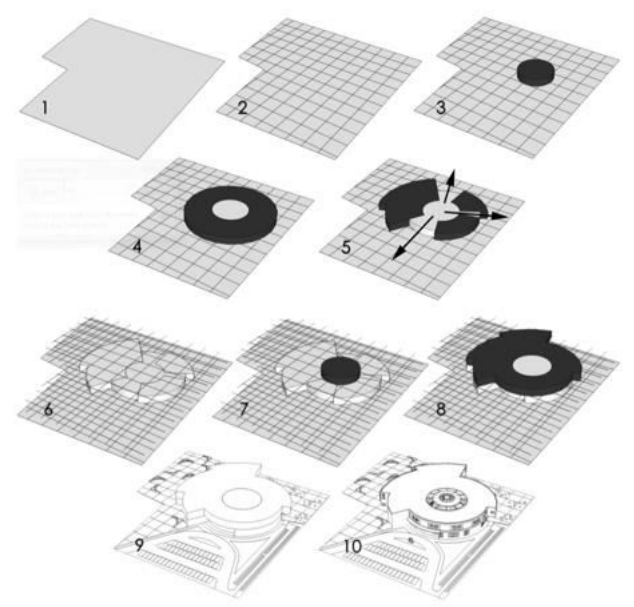

Gambar 5. Transformasi Bentuk.

(Sumber: Dokumen Pribadi)

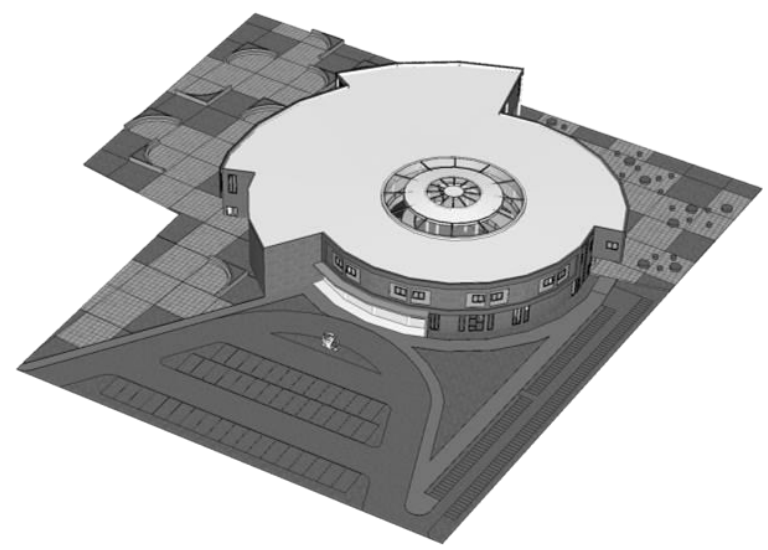

Gambar 6. Desain Tapak Bangunan. (Sumber: Dokumen Pribadi). 


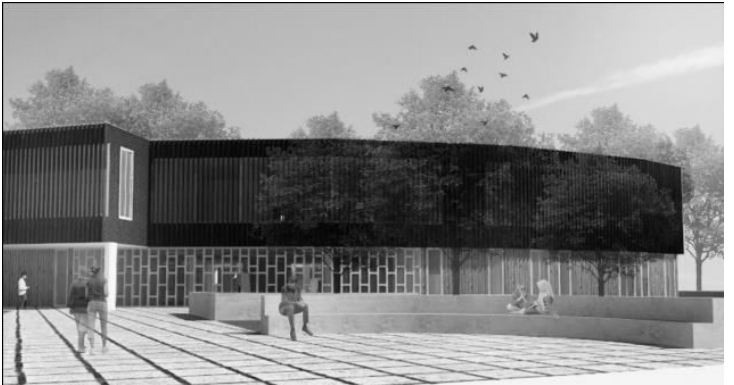

Gambar 7. Pocket Garden.

(Sumber: Dokumen Pribadi)

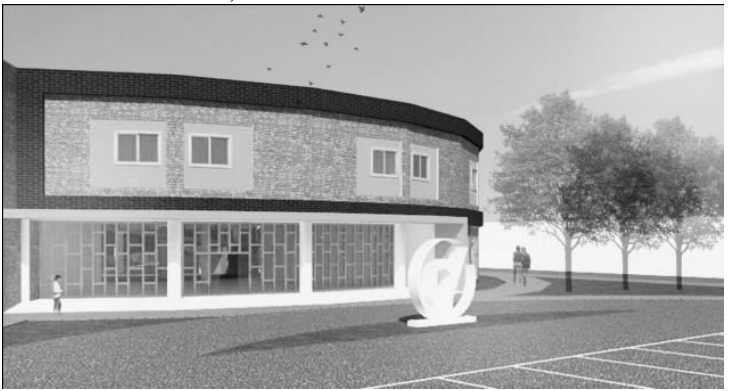

Gambar 8. Landmark pada Bagian Pintu Masuk.

(Sumber: Dokumen Pribadi)

Pada bagian utara tapak, digunakan untuk Pocket Garden yang dilengkapi dengan bangku taman berbentuk pocket atau $\mathrm{U}$ yang sesuai dengan kebutuhan tunarungu dalam berkomunikasi visual (Gambar 7).

Pada bagian depan pintu masuk bangunan, diletakan sebuah landmark berupa ikon dari tunarungu. Selain sebagai identitas bangunan, adanya landmark ini juga sebagai petunjuk arah (navigasi) bagi pengunjung tentang keberadaan pintu masuk (Gambar 8).

Pada bagian selatan tapak, digunakan untuk Flexible Space yang pengaturan tempat duduknya dapat diubah-ubah sesuai dengan kebutuhan dan keinginan pengguna. Flexible Space ini dibuat untuk memenuhi kebutuhan tunarungu akan komunikasi visual. Baik komunikasi visual dengan kelompok kecil hingga besar dapat terwadahi dengan adanya Flexible Space ini (Gambar 9).

Pada tapak juga dilengkapi dengan jalan setapak khusus untuk pejalan kaki. Jalan setapak ini memudahkan tunarungu dalam aspek navigasi, sehingga keamanan dan kenyamanan tunarungu menjadi lebih terjamin (Gambar 10).

\section{B. Konsep Interior}

Pola furnitur pada setiap ruang ditata membentuk pola $\mathrm{O}$ atau $\mathrm{U}$, sehingga akan lebih memudahkan tunarungu dalam melakukan komunikasi visual. Tak hanya itu, untuk memperlancar komunikasi visual, warna-warna yang digunakan pada furnitur dibuat kontras dengan warna kulit (Gambar 11).

Pemakaian material pada lantai, dinding dan juga pattern dari dinding pembatas pada masing-masing ruang dibuat berbeda-beda untuk membantu kesadaran (sensory reach) pada tunarungu ketika berpindah dari satu ruang ke ruang lainnya (Gambar 11 dan 12).



Gambar 9. Flexible Space.

(Sumber: Dokumen Pribadi)

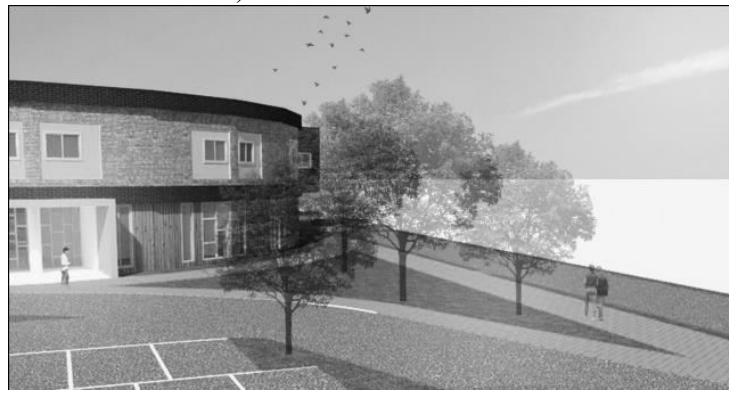

Gambar 10. Jalan Setapak pada Tapak.

(Sumber: Dokumen Pribadi)

Ruang-ruang disekitar area komunitas (pusat sensory) diberi dinding kaca agar fungsi dari setiap ruang tersebut dapat terlihat dengan jelas, selain membantu sensory reach pengguna, hal ini juga dapat membantu sistem navigasi pengguna. Namun dinding kaca tersebut memiliki bukaan yang berbeda-beda sesuai dengan kebutuhan privasi dari masing-masing ruang (Gambar 11 dan 12).

Agar setiap ruang pelatihan mudah dikenali, maka diberikan petunjuk berupa ikon dan warna yang berbeda pada pintu ruangan dari setiap klasifikasi pelatihan yang ada. Dengan demikian pengguna tunarungu akan lebih mudah menemukan ruang pelatihan. Sehingga kebutuhan tunarungu dalam mengenali ruang (sensory reach) dan juga navigasi dapat terpenuhi (Gambar 13).

\section{Konsep Akustik}

Sebagai orang yang memiliki kesulitan untuk mendengar tunarungu memerlukan bantuan akustik ruang agar dapat menangkap suara yang ada. Tak hanya itu, penggunaan alat bantu dengar terkadang juga memiliki resiko untuk telinga ketika mereka berada di ruangan yang memimbulkan suara gema berlebih. Sehingga pada bangunan ini diperlukan pengaturan akustik pada masing-masing ruang sesuai dengan kebutuhannya.

Pada ruang pelatihan dan auditorium yang memerlukan tangkapan suara yang baik untuk pendengar, maka diberikan Gypsum Board pada dinding sebagai pemantul suara agar dapat terdengar oleh tunarungu. Dan untuk menghindari munculnya gema berlebih maka diberikan Foam Acoustic Panel pada plafon. Sedangkan untuk ruang publik seperti galery, area komunitas hingga cafe diberikan Foam Acoustic Panel pada plafon dan juga penggunaan carpet pada lantai sebagai penyerap suara agar tidak terjadi gema (Gambar 14). 


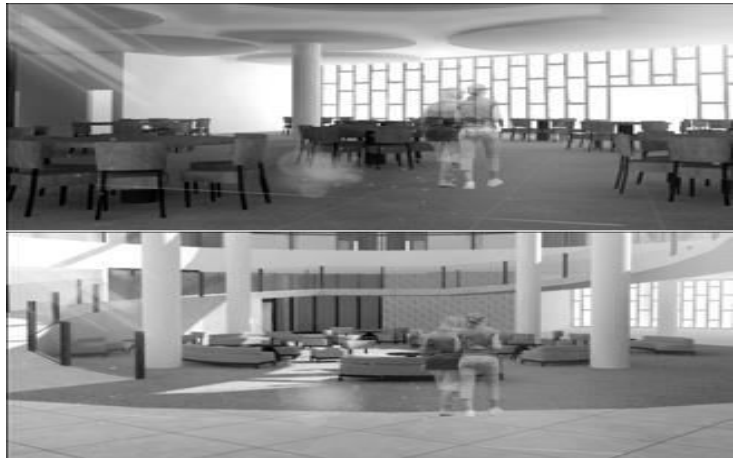

Gambar 11. Interior Cafe dan Area Komunitas.

(Sumber: Dokumen Pribadi)

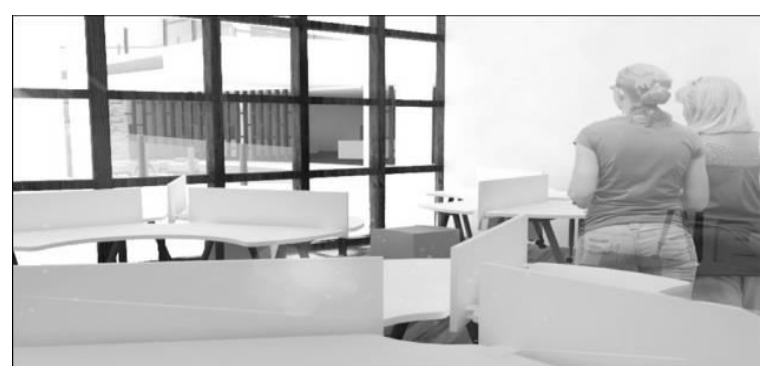

Gambar 12. Interior Ruang Kantor

(Sumber: Dokumen Pribadi)

\section{Konsep Pencahayaan}

Sebagai bangunan yang diperuntukan bagi para tunarungu yang banyak mengandalkan mata, baik untuk komunikasi, sensory reach hingga navigasi, maka pengaturan pencahayaan pada bangunan ini diatur sedemikian rupa agar dapat membuat nyaman mata dan dapat menghindari hal-hal yang dapat membuat mata lelah, seperti silau, dsb.

Bangunan ini memadukan penggunaan pencahayaan buatan dan alami. Setiap ruang pada bangunan ini diberikan bukaan yang dapat memasukan cahaya matahari. Seperti pada area komunitas dimana terdapat skylight di atasnya, sehingga pada siang hari cahaya matahari dapat masuk dan menunjang

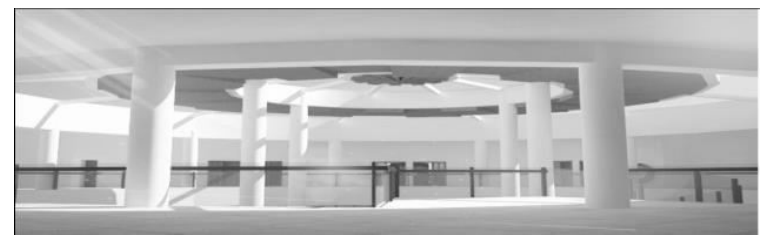

Gambar 15. Skylight pada Bangunan

(Sumber: Dokumen Pribadi)

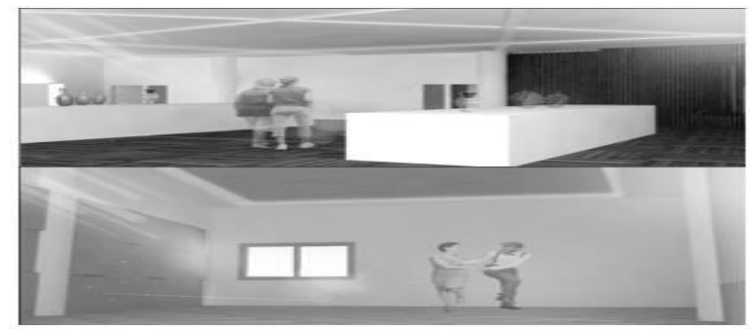

Gambar 16. Indirect Lighting pada Galery dan Ruang Pelatihan (Sumber: Dokumen Pribadi)

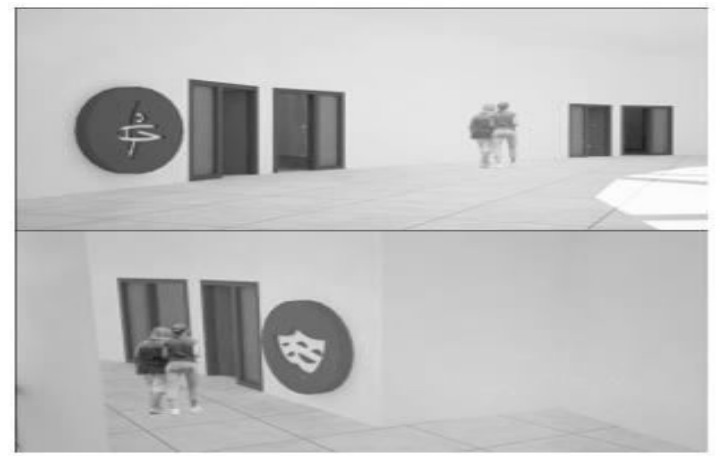

Gambar 13. Penggunaan Ikon dan Warna pada Ruang Pelatihan Minat Bakat. (Sumber: Dokumen Pribadi)

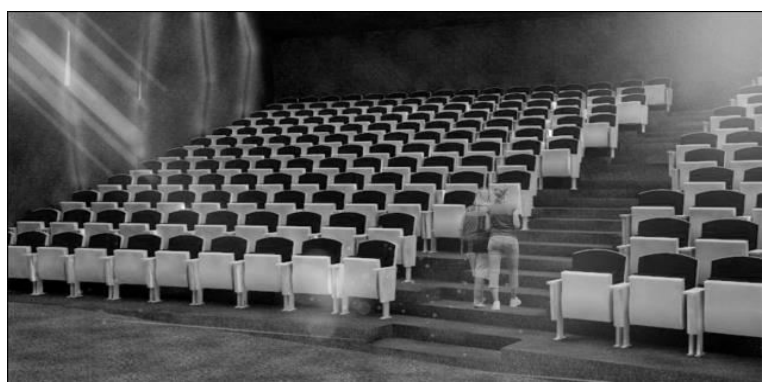

Gambar 14. Pengaturan Akustik pada Auditorium (Sumber: Dokumen Pribadi).

kegiatan yang sedang terjadi (Gambar 15).

Pencahayaan buatan yang digunakan pada area indoor berupa indirect lighting yang dapat memberikan cahaya lembut yang tersebar ke segala sisi, sehingga lebih nyaman dan aman untuk mata (Gambar 16).

Sedangkan untuk area outdoor, dengan luasan taman yang cukup besar, serta adanya jadwal kegiatan yang dapat dilakukan hingga malam hari, maka dibutuhkan pencahayaan buatan pada taman. Pencahayaan buatan pada taman ini berupa diffused pole light yang nyaman dan aman untuk mata. (Gambar 17).

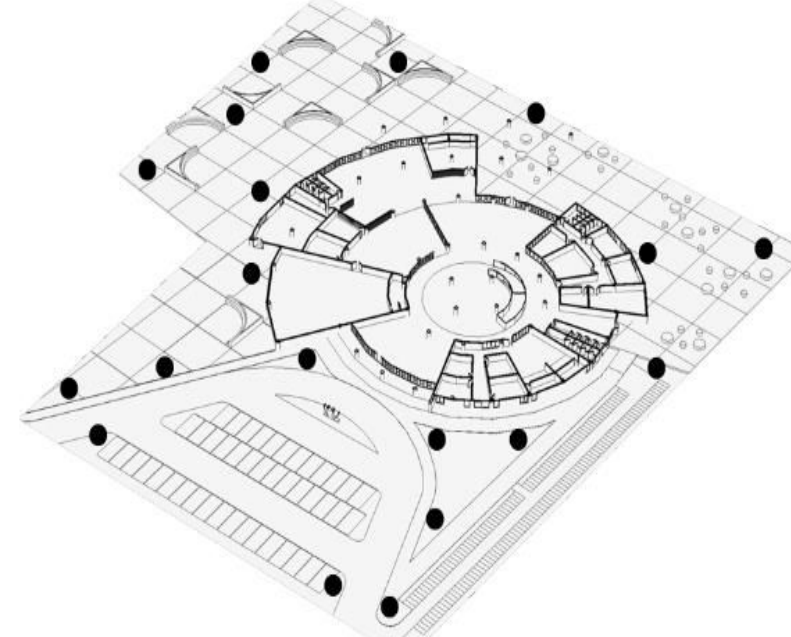

Gambar 17. Skema Peletakan Lampu Taman (Sumber: Dokumen Pribadi) 


\section{KESIMPULAN/RINGKASAN}

Pusat Komunitas Tunarungu dengan konsep Mata yang Mendengar ini hadir sebagai jalan keluar untuk segala permasalahan yang selama ini terjadi pada seorang tunarungu. Pusat Komunitas Tunarungu ini dilengkapi dengan berbagai fasilitas yang dapat mendukung tunarungu dalam menghapus perlakuan diskriminatif yang selama ini mereka terima. Dalam hal ini, selain dilengkapi dengan sarana dan prasarana untuk mengembangkan minat dan bakat, fasilitas ini juga memberikan wadah untuk tunarungu dalam memamerkan minat dan bakatnya kepada masyarakat luas. Dengan melibatkan masyarakat luas ini, diharapkan mampu membuka mata dan pikiran masyarakat tentang sisi lain seorang tunarungu yang selama ini tidak diketahui oleh mereka. Di sisi lain, dengan keterlibatan masyarakat ini juga menguntungkan dari sisi tunarungu karena mereka secara tidak langsung memiliki wadah baru untuk berbaur di tengah masyarakat. Dengan adanya keterlibatan dari kedua belah pihak ini maka diharapkan hubungan yang selama ini tidak baik akan menjadi baik, serta dapat membuka kesempatan tunarungu dalam mencari pekerjaan, sehingga dapat mengubah kualitas hidup seorang tunarungu menjadi lebih baik.

Dari sisi arsitektural, Pusat Komunitas Tunarungu: Mata yang Mendengar ini memiliki desain yang sesuai dengan kebutuhan seorang tunarungu akan sebuah bangunan. Kebutuhan akan Komunikasi Visual, Sensory Reach dan Navigasi (wayfinding) menjadi hal utama yang harus diperhatikan. Dengan terpenuhinya ketiga kebutuhan tersebut, maka bangunan ini menjadi bangunan yang aman dan nyaman bagi tunarungu dalam melakukan berbagai kegiatan di dalamnya.

\section{DAFTAR PUSTAKA}

[1] Kementerian Kesehatan RI, "Buletin Disabilitas Kementerian Kesehatan RI Semester II," 2016.

[2] T. Byrd, "Deaf Space," 2007. [Online]. Available: http://www.gallaudet.edu/campus-design/deafspace.html.

[3] K. Jormakka, Basics Design Method. Birkhäuser, 2008.

[4] B. Tschumi, Six Concepts, Excerpt from Architecture and Disjunction. Cambridge: The MIT Press, 1994.

[5] M. Rin Diani, Mata yang Mendengar: Arsitektur bagi Tunarungu. Jakarta: Suka Buku, 2012. 